\title{
Finger and Palm Prints in Chromatin-positive Males*
}

\author{
H. HUNTER \\ From Balderton Hospital, Balderton, Nr. Newark, Notts.
}

Holt in 1955 provided evidence that total finger ridge count was controlled by a small number of additive genes of appreciable effect. Uchida and Soltan (1963) have suggested that, because of the great diversity of types and combinations of patterns, dermal ridge inheritance is determined by many genes spread over many chromosomes. Penrose (1967) holds that total ridge count is an autosomal trait influenced by the sex chromosomal complement.

The mean total ridge count for males is 144.98 (SD 51.1), and for females 127.23 (SD 52.5) (Holt, 1955). The maximal atd angles vary with age; in the male over the age of 15 years the mean sum of both angles is $85^{\circ}$, and Penrose (1963) gives the single normal as $45^{\circ}$.

The finger and palm pattern characteristics in Klinefelter's syndrome have been described as being very similar to the pattern in normal males, with a slight tendency to more arches (Holt, 1964). The patterns are smaller, with a low total ridge count (Forbes, 1964), and an average total ridge count of 118 (Holt, 1964). The number of ridges between palmar triradii $a$ and $b$ is reduced; the axial triradius is always placed low in the palm.

Uchida, Miller, and Soltan (1964), who analysed the finger and palm prints of 7 cases of XXYY genotype, reported frequent arches and small patterns on the digits and palmar patterns showing 'characteristic configurations of the hypothenar area involving the presence of an ulnar triradius with loop carpel, loop radial, or arch radial pattern'. Patterns compatible with this description were reported by Robinson et al. (1964) in two cases of XXYY.

\section{Methods and Results}

A survey was made of the total male population of all hospitals for the subnormal in the Sheffield Regional Hospital Board area (henceforth referred to as 'present series'). Of the 2103 males examined, 17 were found to have chromatin-positive buccal smears, and a chromosome abnormality was discovered subsequent to blood

Received January 12, 1968.

$\star$ This paper forms part of M.D. thesis, University of London. culture and analysis. Finger and palm prints were obtained in 15 of the 17 cases, the other 2 cases having died before prints could be obtained. Analysis of digital patterns, total digital ridge counts, $\mathrm{a}-\mathrm{b}$ ridge counts, and maximal atd angles yielded the results tabulated in Table I.

Calculations on these results show that the average total digital ridge count for both hands is 115.2 , and reflects the increased number of arches in the finger patterns. Taking only genotype XXY the average becomes 121.7 (SD 55.8), genotype XXYY 91.5 (2 cases), and XXXY 104 ( 1 case).

The XXY genotypes showed no obvious distinctive thenar or hypothenar patterns in 9 instances; 3 however showed hypothenar radial arches.

The 2 XXYY cases showed palmar patterns; in 1 both palms showed well-differentiated hypothenar radial loops, and the right palm also had a parathenar pattern (Fig. 1a and b). Ulnar triradii, described by Uchida et al. (1964), were noted on the left palm, and might have been extralimital on the right palm. The second XXYY patient showed no hypothenar pattern and a $\left(t^{\prime}\right)$ axial triradius on the left palm; the right palm showed a large hypothenar ulnar loop associated with a $\left(t^{\prime}\right)$ axial triradius (Fig. 2a and b).

The mean maximal atd angle for XXY was 79.83 (SD 8.72) and the average for XXYY was 98.5. Of the 30 palms, $24(83.0 \%)$ had angles below $44^{\circ}$. The a-b ridge counts show that genotype XXY has a mean count (sum of both hands) of 85.1 (SD 13.9) and XXYY 87.5.

\section{Discussion}

Digital Patterns. From study of Table I an impression is gained that there is an over-all increase in the number of simple pattern types. To test this suggestion, the frequency of digital arch patterns in the present series of genotypes XXY and XXYY was compared with those of a Canadian group and their controls (Uchida et al., 1964), as shown in Table II. The single case of XXXY has been included for completion.

Assuming that any possible differences between Canadian and English populations are not large, we may accept the $2.9 \%$ incidence of arch patterns in normal Canadian men as suitable controls for English Klinefelter cases. With this proviso, the present results support the suggestion of an increased 
TABLE I

FINGER AND PALM PRINT ANALYSIS IN 15 CHROMATIN-POSITIVE MALES

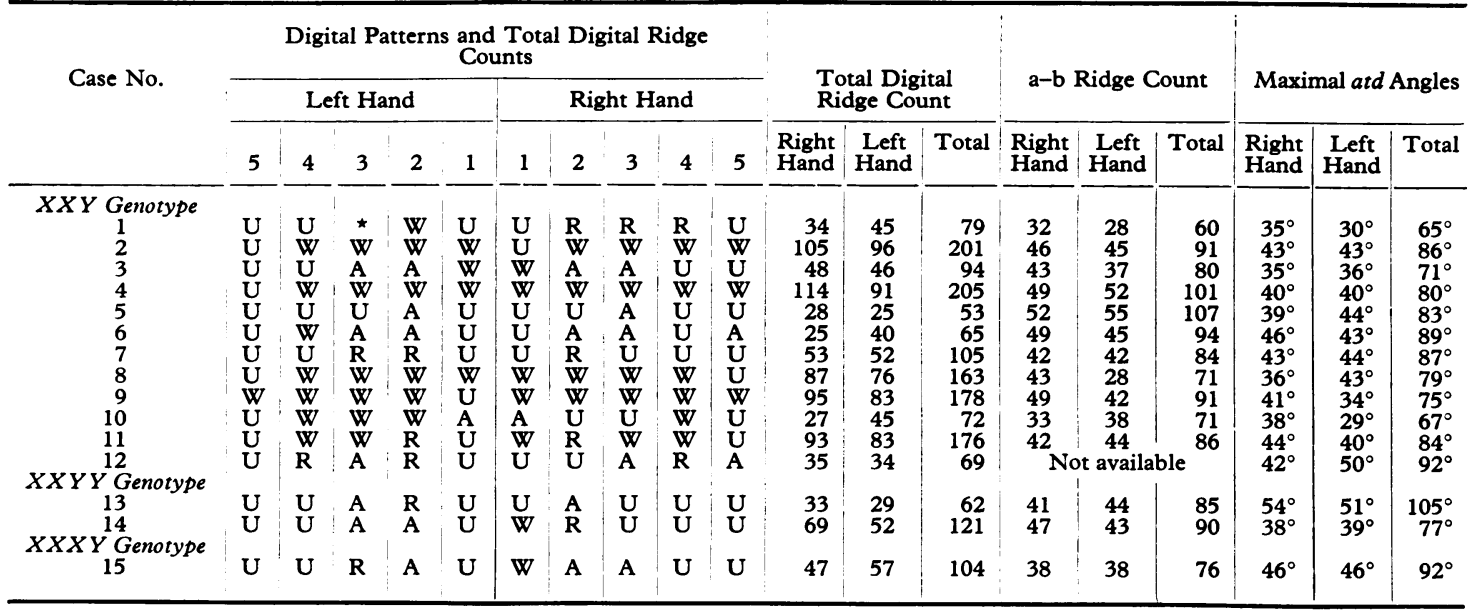

W, whorl; A, arch; $R$, loop radial; $U$, loop ulnar; *, finger missing.

number of digital arch patterns in XXYY cases. As regards XXY genotype, the variation of arch frequency among the present series appears to be greater and shows a higher incidence than the Canadian XXY cases. However, the over-all result is in accord with the description by Holt (1964).

Total Digital Ridge Count. Pooling the present results with XXY, XXYY, and XXXY cases provided by S. B. Holt (personal communication), and a further case of XXYY (Ellis et al., 1961), Table III was constructed. Control data were obtained from Holt (1955).

Comparison of differences between the total digital ridge counts of control and XXY males gave highly significant results $(p<0.001,871$ d.f.; $t=3.39$ ). Although the mean counts for genotype $\mathrm{XXYY}$ and $\mathrm{XXXY}$ are smaller than those of XXY, the number of cases is too small to compare satisfactorily.

a-b Ridge Counts. Significant differences in $a-b$ ridge counts exist between the sexes (Holt and Lindsten, 1964). In certain sex chromosome anomalies, e.g. Turner's syndrome, the triradius $b$ tends to move to the ulnar side, creating an increased distance $a-b$ and a related increased mean ridge count (Penrose, 1963). No specific count

TABLE II

FREQUENCIES OF SIMPLE ARCH PATTERNS ON DIGITS OF GENOTYPES XXY, XXYY, AND CONTROLS (MODIFIED FROM UCHIDA et al., 1964)

\begin{tabular}{|c|c|c|c|c|c|c|c|}
\hline \multirow{2}{*}{$\begin{array}{l}\text { No. of Arches } \\
\text { per Person }\end{array}$} & \multirow{2}{*}{$\underset{(1)}{\operatorname{XXXY}}$} & \multicolumn{2}{|c|}{ XXYY } & \multicolumn{2}{|c|}{ XXY } & \multicolumn{2}{|c|}{ Controls } \\
\hline & & $\begin{array}{c}\text { Present Series } \\
\text { (2) }\end{array}$ & $\underset{(7)}{\text { Canadian }}$ & $\begin{array}{c}\text { Present Series } \\
\text { (12) }\end{array}$ & $\begin{array}{c}\text { Canadian } \\
(23)\end{array}$ & $\begin{array}{l}\text { Male } \\
\text { (353) }\end{array}$ & $\begin{array}{c}\text { Female } \\
(342)\end{array}$ \\
\hline $\begin{array}{r}0 \\
1 \\
2 \\
3 \\
4 \\
5 \\
6 \\
7 \\
8 \\
9 \\
10\end{array}$ & 1 & $\begin{array}{l}\bar{z} \\
\bar{z} \\
\bar{z} \\
\bar{z} \\
\end{array}$ & $\begin{array}{l}\frac{4}{1} \\
\frac{1}{E} \\
= \\
\frac{1}{-}\end{array}$ & $\begin{array}{l}\frac{7}{2} \\
1 \\
1 \\
= \\
= \\
=\end{array}$ & $\begin{array}{l}16 \\
\frac{4}{2} \\
\frac{1}{1} \\
= \\
=\end{array}$ & $\begin{array}{r}306 \\
21 \\
12 \\
8 \\
2 \\
2 \\
1 \\
-1 \\
-1\end{array}$ & $\begin{array}{r}265 \\
31 \\
15 \\
13 \\
4 \\
2 \\
6 \\
2 \\
1 \\
3\end{array}$ \\
\hline $\begin{array}{l}\text { Total No. } \\
\text { Percentage }\end{array}$ & $\begin{array}{r}5 \\
50\end{array}$ & 20 & $\begin{array}{l}14 \\
20\end{array}$ & $16 \cdot 3$ & $\begin{array}{l}15 \\
6.5\end{array}$ & $\begin{array}{r}102 \\
2.9\end{array}$ & $\begin{array}{c}204 \\
6.0\end{array}$ \\
\hline
\end{tabular}



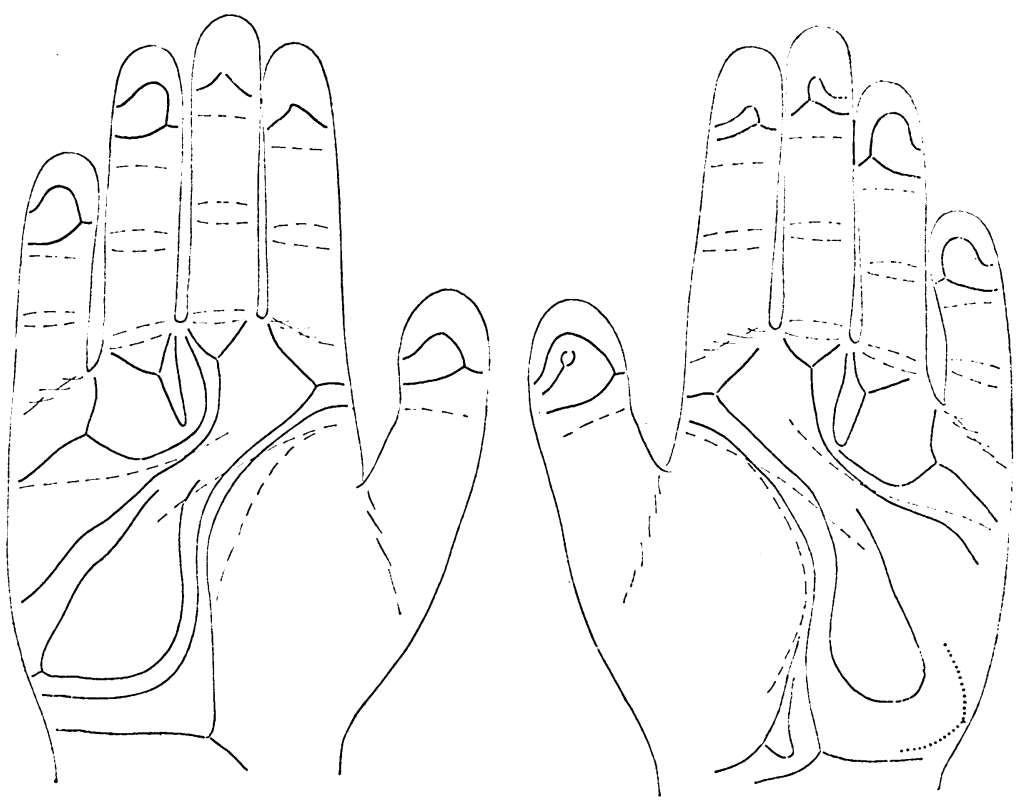

Fig. 1a and b. Left and right hands of an XXYY patient (Case 13).
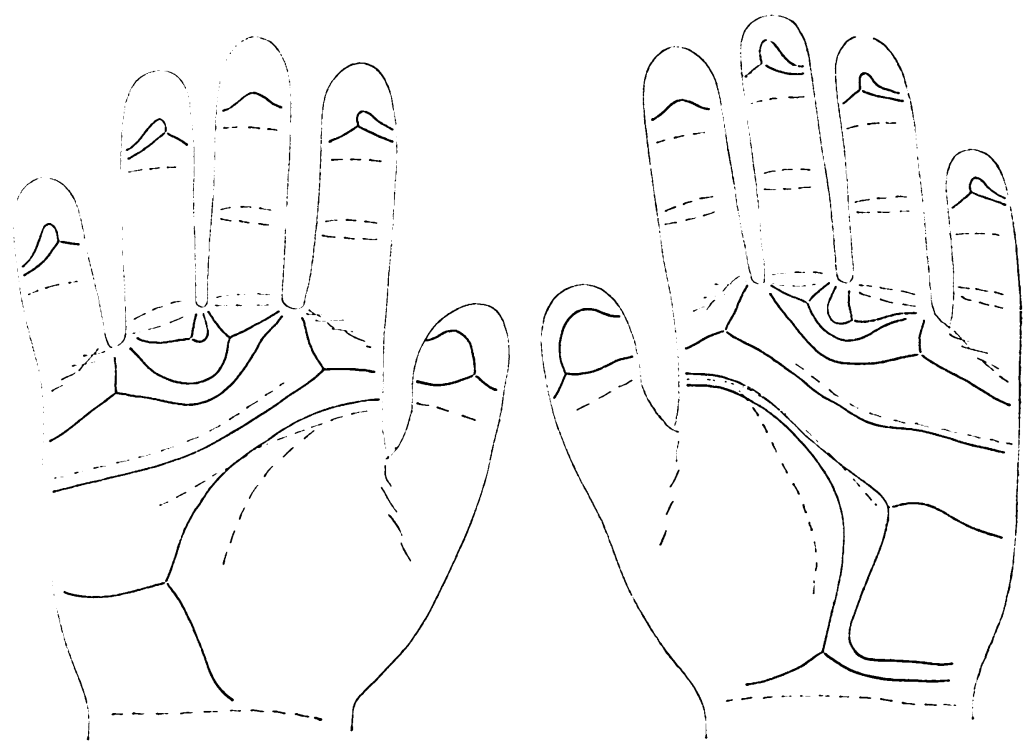

FIG. 2a and b. Left and right hands of an XXYY patient (Case 14).

difference in Klinefelter's syndrome is mentioned in the available literature.

Using data from S. B. Holt (personal communication), 36 cases of XXY were pooled with the 11 cases from the present series (Table IV). The $a-b$ count proved just significantly lower than that of the control group $(t=2.3 ; 84$ d.f.; $p<0.05)$.
The two cases of XXYY in this series have a mean a-b ridge count of 87.5 , which is not appreciably different from that of the normal controls.

Maximal atd Angles. The frequency and distribution of the maximal atd angles in relation to the genotypes are shown in Table V. 
TABLE III

TOTAL DIGITAL RIDGE COUNTS FOR BOTH HANDS: COMPARISON BETWEEN NORMAL AND CHROMATIN-POSITIVE MALES

\begin{tabular}{|c|c|c|c|c|c|c|c|c|c|c|}
\hline \multirow{2}{*}{ Source } & \multicolumn{3}{|c|}{ Controls } & \multicolumn{3}{|c|}{ XXY } & \multicolumn{2}{|c|}{ XXYY } & \multicolumn{2}{|c|}{$\mathbf{X X X Y}$} \\
\hline & No. & Mean & SD & No. & Mean & SD & No. & Mean & No. & Mean \\
\hline $\begin{array}{l}\text { Present series } \\
\text { Holt (1955) } \\
\text { Ellis et al. (1961) }\end{array}$ & & & & $\begin{array}{l}12 \\
36\end{array}$ & $\begin{array}{l}121 \cdot 7 \\
118 \cdot 7\end{array}$ & $\begin{array}{l}55 \cdot 8 \\
39 \cdot 0\end{array}$ & $\begin{array}{l}2 \\
2 \\
1 \\
\end{array}$ & $\begin{array}{l}91 \cdot 5 \\
96.5 \\
68 \cdot 0 \\
\end{array}$ & $\begin{array}{l}1 \\
3\end{array}$ & $\begin{array}{l}104 \cdot 0 \\
117 \cdot 0\end{array}$ \\
\hline Total & 825 & 144.9 & $43 \cdot 2$ & 48 & ${ }^{\star} 119 \cdot 4$ & $43 \cdot 2$ & 5 & $88 \cdot 8$ & 4 & 114.0 \\
\hline
\end{tabular}

TABLE IV

a-b RIDGE COUNTS (SUM OF BOTH HANDS): COMPARISON BETWEEN NORMAL AND CHROMATIN-POSITIVE MALES

\begin{tabular}{|c|c|c|c|c|c|c|c|c|c|c|}
\hline \multirow{2}{*}{ Source } & \multicolumn{3}{|c|}{ Controls } & \multicolumn{3}{|c|}{$\mathbf{X X Y}$} & \multicolumn{2}{|c|}{ XXYY } & \multicolumn{2}{|c|}{ XXXY } \\
\hline & No. & Mean & SD & No. & Mean & SD & No. & Mean & No. & Mean \\
\hline $\begin{array}{l}\text { Present series } \\
\text { S.B. Holt (personal } \\
\text { communication) } \\
\text { Holt and Lindsten } \\
\text { (1964) }\end{array}$ & 39 & $87 \cdot 9$ & $8 \cdot 56$ & $\begin{array}{l}11 \\
36\end{array}$ & $\begin{array}{l}85 \cdot 1 \\
81 \cdot 92\end{array}$ & $\begin{array}{l}13.9 \\
11.51\end{array}$ & $\begin{array}{l}2 \\
2\end{array}$ & $\begin{array}{l}87 \cdot 5 \\
80 \cdot 0\end{array}$ & $\begin{array}{l}1 \\
3\end{array}$ & $\begin{array}{l}76 \cdot 0 \\
82 \cdot 3\end{array}$ \\
\hline Totals & 39 & $87 \cdot 9$ & 8.56 & 47 & $82 \cdot 67 \star$ & $11 \cdot 98$ & 4 & $83 \cdot 2$ & 4 & $80 \cdot 7$ \\
\hline
\end{tabular}

* Significant differences from controls. $t=2.3 ; 84$ d.f.; $p<0.05$.

TABLE V

MAXIMAL atd ANGLE:

FREQUENCY AND DISTRIBUTION IN CHROMATIN-POSITIVE GENOTYPES

\begin{tabular}{l|c|c|c|c|c|c|c}
\hline & $\begin{array}{c}\text { No. of } \\
\text { Patients }\end{array}$ & $25-29^{\circ}$ & $30-34^{\circ}$ & $35-39^{\circ}$ & $40-44^{\circ}$ & $45-49^{\circ}$ & $50-54^{\circ}$ \\
\hline XXY & 12 & 1 & $\frac{2}{2}$ & 6 & $\frac{13}{2}$ & $\frac{1}{2}$ & $\frac{1}{2}$ \\
XXYY & 2 & - & $\frac{-}{2}$ & - & - & 2 & - \\
\hline Total & 15 & 1 & 2 & 8 & 13 & 3 & 3 \\
\hline
\end{tabular}

Not too much reliance must be placed on the atd angle, as differences in technique, such as spreading the fingers or holding them in juxtaposition, can make alterations of $10^{\circ}$ or more (Uchida and Soltan, 1963); this probably applies more to children than to adults. Nevertheless, examination of the figures suggests that chromatin-positive Klinefelter males have a more acute atd angle than normal.

Not enough measurements are available to state positively that XXYY have smaller atd angles than $\mathrm{XXY}$. There is perhaps a slight tendency shown in that direction, which would be in keeping with the extra long limbs of XXYY patients.

Pattern Intensity and Sex Chromosomes. Increasing numbers of sex chromosomes appear to have a negative correlation with the intensity of the finger print pattern. The analysis presented here suggests that, as the genotypes increase in complexity from $\mathrm{XY}$ through $\mathrm{XXY}$ and $\mathrm{XXYY}$ to $\mathrm{XXXY}$, the frequency of arch digital patterns increases.

(i) Digital Ridge Count. The decrease in pattern intensity is more clearly seen as the pooled mean values of the total digital ridge counts are followed. Thus, XY, XXY, XXXY, and XXYY have scores of $145,120,114$, and 89 , respectively.

Penrose (1963) suggested that an increasing number of $\mathrm{X}$ chromosomes was associated with decreased, finger print intensity. Taking into consideration the raised total digital ridge count in Turner's syndrome with the findings of this analysis, Penrose's hypothesis is strongly supported. Holt and Lindsten (1964) reported the mean total digital ridge count in XO cases as 166; they also 
TABLE VI

MEAN TOTAL DIGITAL RIDGE COUNT: EFFECT OF X AND Y CHROMOSOMES

\begin{tabular}{|c|c|c|c|c|c|c|c|c|c|c|}
\hline \multirow[b]{2}{*}{ Genotype } & \multicolumn{5}{|c|}{ Effect of X Chromosomes } & \multicolumn{5}{|c|}{ Effect of Y Chromosomes } \\
\hline & $\mathbf{x X}$ & XO & $\mathbf{X Y}$ & $\mathbf{X X Y}$ & $\mathbf{X X X Y}$ & XO & $\mathbf{X Y}$ & $\mathbf{X X}$ & XXY & XXYY \\
\hline Mean total digital ridge count & 128 & 166 & 145 & 120 & 114 & 166 & 145 & 128 & 120 & 89 \\
\hline $\begin{array}{l}\text { Difference } \\
\text { Remarks }\end{array}$ & \multicolumn{2}{|c|}{$\begin{array}{c}38 \\
\text { Significant }\end{array}$} & \multicolumn{3}{|c|}{$\underbrace{25}_{\text {Significant }}$ NS } & \multicolumn{2}{|c|}{$\begin{array}{c}21 \\
\text { Significant }\end{array}$} & \multicolumn{2}{|c|}{$\begin{array}{c}8 \\
\text { NS }\end{array}$} & $\begin{array}{l}31 \\
\text { NS }\end{array}$ \\
\hline
\end{tabular}

TABLE VII

MEAN a-b RIDGE COUNTS (SUM OF BOTH HANDS) EFFECT OF X AND Y CHROMOSOMES

\begin{tabular}{|c|c|c|c|c|c|c|c|c|c|c|}
\hline \multirow[b]{2}{*}{ Genotype } & \multicolumn{5}{|c|}{ Effect of X Chromosome } & \multicolumn{5}{|c|}{ Effect of Y Chromosome } \\
\hline & Xo & $\mathbf{x x}$ & $\mathbf{X Y}$ & $\mathrm{XXY}$ & $\mathrm{XXXY}$ & xo & $\mathbf{X Y}$ & $\mathbf{x x}$ & $\mathbf{X X Y}$ & $\mathrm{XXYY}$ \\
\hline Mean total $a-b$ ridge count & 98 & 84 & 88 & 83 & 81 & 98 & 88 & 84 & 83 & 83 \\
\hline $\begin{array}{l}\text { Difference } \\
\text { Remarks }\end{array}$ & $\underset{\text { signi }}{H}$ & canty & $\underbrace{}_{\text {Sign }}$ & $\begin{array}{l}5 \\
\text { ificant }\end{array}$ & $\stackrel{2}{\text { NS }}$ & $\begin{array}{r}\text { Hig } \\
\text { signi }\end{array}$ & hicant & $\mathrm{N}$ & & $\begin{array}{c}0 \\
\text { NS }\end{array}$ \\
\hline
\end{tabular}

TABLE VIII

MEAN MAXIMAL atd ANGLE, INCREASING X AND Y CHROMOSOMES

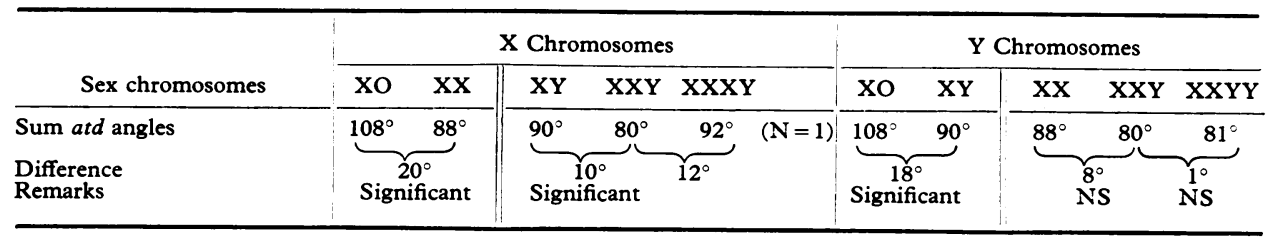

found that this was not significantly different from normal male controls (150) but very significantly different from female controls (130). The control group was small and drawn from a Swedish population.

From the data (Table III) it will be seen that insufficient cases of XXYY and XXXY have been described to permit satisfactory statistical analysis. Bearing this in mind and taking the control group of 825 as the mean of the normal population, it can be shown that the mean of the XXYY cases is significantly lower than that of the controls $(z=2.9$; $p=<0.0038$ ). By the same procedure XXXY does not differ significantly from the mean of the controls $(z=1 \cdot 66)$. Using a $t$ test, the $X X Y$ cases proved highly significantly different from the controls $(t=$ 3.39; d.f. 871, $\mathrm{p}<0.001$ ).

Substituting quantitative measurements for chromosomes, the following simple chart was produced (Table VI). This illustrates that by increasing the number of $\mathrm{X}$ chromosomes ( $\mathrm{XO}$ to $\mathrm{XX}$ and $\mathrm{XY}$ to $\mathrm{XXY}$ ) significant reduction in the mean total digital ridge count occurs.

Any effect of the $\mathrm{Y}$ chromosome on the mean total digital ridge count is more difficult to evaluate. At first sight a trend of a decreasing count with increasing numbers of $\mathrm{Y}$ chromosomes appears apparent, and the transition of XO to XY has the tendency to lower the score significantly (Table VI). However, no significant differences exist between $\mathrm{XX}, \mathrm{XXY}$, and XXYY. From this it seems that if the $\mathrm{Y}$ chromosome does affect the total ridge count, it does so only slightly.

(ii) $a-b$ Ridge Counts (Sum of Both Hands). The $\mathrm{a}-\mathrm{b}$ ridge count is also affected by sex chromosome aneuploidy. Holt and Lindsten (1964) gave mean counts for Turner's syndrome, normal males and females as $97 \cdot 9,87 \cdot 9$, and $83 \cdot 7$, respectively. Comparing differences between XO and normal female controls they found highly significant results. In this study a significant difference was found between $X Y$ and XXY. No obvious difference appears to exist between XXY and XXXY, but insufficient numbers of cases makes this calculation unreliable. Pooling these results, a table of comparisons of differing $\mathrm{X}$ chromosome frequency can be constructed (Table VII). This shows that with in- 
creasing $\mathrm{X}$ chromosomes the mean $\mathrm{a}-\mathrm{b}$ ridge count tends to decrease, and that this decrease reaches significant levels.

If the effect of the $Y$ chromosome is considered the results are not nearly so dramatic (Table VII). The difference between $\mathrm{a}-\mathrm{b}$ ridge counts of $\mathrm{XO}$ and control males is highly significant (Holt and Lindsten, 1964). Between control females (XX) and Klinefelters XXY and XXYY, there are no differences.

From this it is concluded that the $\mathrm{X}$ chromosome tends to cause greater variation in the ridge count between palmar triradii $a$ and $b$ than does the $Y$ chromosome.

(iii) Maximal atd Angles. Significant differences in maximal atd angles exist between Turner's syndrome (XO) and control males and females (Holt and Lindsten, 1964). Comparison of this series of XXY cases with the control males provided significant differences $(t=2.07$; d.f. $49 ; \mathrm{p}=<0.5)$, and showed that the XXY had more acute atd angles. Similar calculations with the control females gave a decreased maximum atd angle which did not reach significant levels of differences $(t=$ 1.95 ; d.f. $60 ; \mathrm{p}<0 \cdot 1)$.

To show any possible differential effects of $\mathrm{X}$ and $\mathrm{Y}$ chromosomes on this measurement, Table VIII was constructed. The results show that both extra $\mathrm{X}$ and $\mathrm{Y}$ chromosomes each individually tend to decrease the maximal atd angle. However, this effect only reaches significance in the presence of the supernumerary $\mathrm{X}$ chromosome.

\section{Summary}

Digital arch patterns are increased in chromatinpositive Klinefelters. Genotype XXY has an increased digital arch pattern frequency over normal, while XXYY has a greater increased frequency than both. The total digital ridge count for both hands in genotype XXY is significantly smaller than controls. Similarly, this count is reduced in genotypes $\mathrm{XXYY}$ and XXXY, but because of insufficient numbers, the results are less reliable.

The palm prints described here support the observation that genotype XXYY tends to have hypothenar patterns. However, one case showed either no hypothenar pattern or no ulnar triradius in the two palm prints. Moreover, radial loop hypothenar patterns were found in three cases of XXY. The maximal atd angle was found to be narrower than normal in most of the chromatin-positive males described here.

Evidence is adduced that the effects of the $\mathrm{X}$ chromosome on dermatoglyphs are greater than those of the $\mathrm{Y}$ chromosome. A negative correlation appears to exist between the number of $X$ chromosomes and the total digital ridge count, $\mathrm{a}-\mathrm{b}$ ridge count, and maximal atd angle.

I should like to express my gratitude to the Research Committee of the Sheffield Regional Hospital Board without whose research grant this survey would not have been performed; to Dr. K. O. Milner, Medical Superintendent, Aston Hall Hospital, Dr. A. A. Valentine, Medical Superintendent, Glenfrith Hospital, Dr. J. McHugh, Medical Superintendent, Whittington Hall Hospital, and Dr. J. S. Robson, Medical Superintendent, Harmston Hall Hospital, for giving me permission to examine their patients; and to the nursing and administrative staff of the various hospitals for their co-operation.

\section{REFERENCES}

Ellis, J. R., Miller, O. J., Penrose, L. S., and Scott, G. E. B. (1961). A male with XXYY chromosomes. Ann. hum. Genet., 25, 145.

Forbes, A. P. (1964). Finger prints and palm prints (dermatoglyphics) and palmar flexion creases in gonadal dysgenesis, pseudohypoparathyroidism and Klinefelter's syndrome. New Engl. $\mathcal{F}$. Med., 270, 1268.

Holt, S. B. (1955). Genetics of dermal ridges; frequency distributions of total finger ridge-count. Ann. hum. Genet., 20, 159.

(1964). The role of dermatoglyphics in medical biology. Med. Wld (Lond.), 101, 112.

, and Lindsten, J. (1964). Dermatoglyphic anomalies in Turner's syndrome. Ann. hum. Genet., 28, 87.

Penrose, L. S. (1963). Finger-prints, palms and chromosomes. Nature (Lond.), 197, 933.

(1967). Finger print pattern and the sex chromosomes. Lancet, 1, 298.

Robinson, G. C., Miller, J. R., Dill, F. R., and Kamburoff, T. D. (1964). Klinefelter's syndrome with the XXYY sex chromosome complex. F. Pediat., 65, 226.

Uchida, I. A., Miller, J. R., and Soltan, H. C. (1964). Dermatoglyphics associated with the XXYY chromosome complement. Amer. F. hum. Genet., 16, 284.

-, and Soltan, H. C. (1963). The evaluation of dermatoglyphics in medical genetics. Pediat. Clin. N. Amer., 10, 409.

\section{Addendum}

Since this paper was prepared, further evidence has been published which tends to support that presented here. This is especially so with the total digital ridge count which has been more fully analysed and discussed, and a mechanism of embryonic oedema or dehydration has been advanced as a possible explanation (Penrose,
1967). 